\title{
Scale development and utilization of universal PCR-based and high-throughput KASP markers specific for chromosome arms of rye (Secale cereale L.)
}

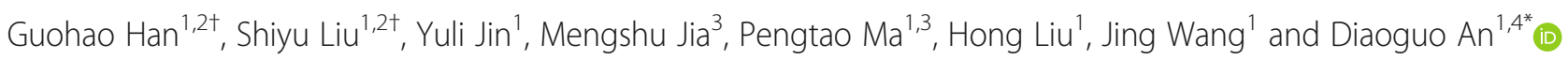

\begin{abstract}
Background: Rye (Secale cereale L., $2 n=2 x=14, R R$ ), a relative of common wheat, is a large gene resource pool for wheat improvement. Accurate and convenient identification of the rye chromatin in wheat background will facilitate the transfer and utilization of elite genes derived from rye in wheat breeding.

Results: In the present study, five rye cultivars including Imperial, German White, Jingzhouheimai, Baili and Guyuan were sequenced by specific-locus amplified fragment sequencing (SLAF-seq) to develop large-scale rye-specific markers. Based on SLAF-seq and bioinformatics analyses, a total of 404 universal PCR-based and a whole set of Kompetitive allele-specific PCR (KASP) markers specific for the 14 individual rye chromosome arms were developed and validated. Additionally, two KASP markers specific for 1RS and 2RL were successfully applied in the detection of $1 \mathrm{RS}$ translocations in a natural population and $2 \mathrm{RL}$ chromosome arms in wheat-rye derived progenies that conferred adult resistance to powdery mildew.

Conclusion: The 404 PCR-based markers and 14 KASP markers specific for the 14 individual rye chromosome arms developed in this study can enrich the marker densities for gene mapping and accelerate the utilization of rye-derived genes in wheat improvement. Especially, the KASP markers achieved high-throughput and accurate detection of rye chromatin in wheat background, thus can be efficiently used in marker-assisted selection (MAS). Besides, the strategy of rye-specific PCR-based markers converting into KASP markers was high-efficient and low-cost, which will facilitate the tracing of alien genes, and can also be referred for other wheat relatives.
\end{abstract}

Keywords: Rye, Chromosome-specific marker, KASP marker, MAS, Wheat

\footnotetext{
* Correspondence: dgan@sjziam.ac.cn

${ }^{\dagger}$ Guohao Han and Shiyu Liu contributed equally to this work.

${ }^{1}$ Center for Agricultural Resources Research, Institute of Genetics and

Developmental Biology, Chinese Academy of Sciences, Shijiazhuang 050021,

Hebei, China

${ }^{4}$ The Innovative Academy of Seed Design, Chinese Academy of Sciences, Beijing, China

Full list of author information is available at the end of the article
}

(c) The Author(s). 2020 Open Access This article is licensed under a Creative Commons Attribution 4.0 International License, which permits use, sharing, adaptation, distribution and reproduction in any medium or format, as long as you give appropriate credit to the original author(s) and the source, provide a link to the Creative Commons licence, and indicate if changes were made. The images or other third party material in this article are included in the article's Creative Commons licence, unless indicated otherwise in a credit line to the material. If material is not included in the article's Creative Commons licence and your intended use is not permitted by statutory regulation or exceeds the permitted use, you will need to obtain permission directly from the copyright holder. To view a copy of this licence, visit http://creativecommons.org/licenses/by/4.0/ The Creative Commons Public Domain Dedication waiver (http://creativecommons.org/publicdomain/zero/1.0/) applies to the data made available in this article, unless otherwise stated in a credit line to the data. 


\section{Background}

Common wheat (Triticum aestivum L.) is a major grain crop worldwide. With the expanding global population to nine billion by 2050, wheat production is facing a challenge of about $70 \%$ growth to meet the demands in the future [1]. However, wheat breeding mainly focused on crossing between cultivars for a long time, which resulted in more homogeneous genetic backgrounds and narrowed genetic diversity in wheat breeding [2]. The wheat relatives have significant genetic diversity and abundant valuable genes, therefore can play an important role in wheat improvement [3]. To date, many elite alien genes and desirable traits have been transferred into common wheat through hybridization and chromosome engineering, such as disease resistance, superior yield-related traits, salt and drought tolerance [4-7].

Rye (Secale cereale L., $2 \mathrm{n}=2 \mathrm{x}=14, \mathrm{RR}$ ), a naturally cross-pollinated relative of common wheat, can be used as a huge gene donor for wheat improvement. For example, the wheat-rye T1RS.1BL translocation derived from rye cultivar Petkus carries the powdery mildew resistance gene $\mathrm{Pm} 8$, stripe rust resistance gene $\mathrm{Yr}$ 9, leaf rust gene $\operatorname{Lr} 26$ and stem rust resistance gene $\operatorname{Sr} 31$ [8, 9], along with superior agronomic traits and abiotic stress tolerance $[10,11]$. Therefore, the T1RS.1BL translocation has been widely used worldwide and was regarded as a particular notable success in crop improvement of alien chromosomes [12, 13]. Apart from the 1RS, some other chromosomes of rye carrying resistance genes have also been transferred into common wheat in forms of translocations, including $P m 7$ and $L r 25$ on 2 RL from rye cultivar Rosen [14, 15], Lr45 on 2RL from rye cultivar Petkus [16], Sr59 on 2RL from triticale VTB28041 [17], Sr27 on 3RS from rye cultivar Imperial [18], Pm56 on 6RS from rye cultivar Qinling [19] and Pm20 on 6RL from rye cultivar Prolific [14]. In addition, increasing rye-derived genes have been used in wheat improvement in recent years. For example, Schneider et al. [12] demonstrated that chromosome $1 \mathrm{R}, 4 \mathrm{R}$, and $6 \mathrm{R}$ from rye cultivar Perennial could increase arabinoxylan and protein content after transferring into wheat background. A wheat-rye $4 R$ addition line increased kernel number per spike after the $4 R$ transferring into wheat [20].

After transferring alien chromatin into common wheat, it is important to develop rapid, accurate and convenient methods to trace them. Genomic in situ hybridization (GISH) and fluorescence in situ hybridization (FISH), especially multicolor FISH (mc-FISH), are widely-used detection methods owing to intuitive and accurate specialty $[21,22]$. Meanwhile, molecular markers specific for alien chromosomes are also powerful for detecting alien chromatin in wheat background [23]. Therefore, a highefficient strategy for developing specific molecular markers played a key role in the utilization of alien genes.
Despite a series of rye-specific markers have been reported [24-28], it is still in a large demand when applied in highresolution mapping, population genetic studies and marker assisted selection (MAS). In addition, as a crosspollinated crop, rye contains significant genetic heterogeneity within and among cultivars [29, 30]. This will limit the universality of the specific markers in different rye genetic backgrounds. Therefore, it is necessary to develop a large number of universal, stable and easily performed markers for construction of high-density map of rye, detection of rye chromatin in wheat backgrounds and MAS.

With rapid advancement of next-generation sequencing technology (NGS) and low-cost genome sequencing, an increasing number of single nucleotide polymorphism (SNP) markers were developed attributing to their high stability, high resolution and low cost, and therefore are suitable for large-scale genotyping [31-33]. On this basis, Kompetitive allele-specific PCR (KASP) assay method, as one of current SNP assay platforms, has been successfully used to identify alien chromatin in wheat background, which can accelerate the tracking of alien fragments and improved the efficiency of MAS [34]. However, many wheat relatives are short of high-quality whole-genome sequence, which has limited the development of KASP markers for the detection of alien segments on a large scale.

In this study, an efficient NGS method specific-locus amplified fragment sequencing (SLAF-seq) and bioinformatics analyses were combined to develop a large number of universal PCR-based markers distributed on all the chromosome arms of rye. Then, these markers were analyzed to generate a set of KASP markers specific for each arm of the rye chromosome. Furthermore, these KASP markers were validated and applied in MAS on scale. The strategy for development of KASP markers adopted in this study can be a good reference for other wheat relatives.

\section{Results \\ Development and verification of universal PCR-based markers}

Based on the results of high-throughput sequencing method SLAF-seq for the five rye cultivars, including Imperial, German White, Jingzhouheimai, Baili and Guyuan, a total of 653,144 SLAFs were acquired. The average Q30 ratio was $86.79 \%$, indicating that the data has high quality. By sequence alignment between the five rye cultivars and Chinese Spring [35], 3871 sequences with homology less than $50 \%$ of wheat genome were obtained and considered as the conserved and rye-specific sequences. A total of 1546 SLAFs were randomly selected to design rye-specific PCR-based primers. Among them, 667 primers which amplified specific bands in all the five rye cultivars plus KingII but not in the wheat 
cultivar Holdfast were regarded as the universal ryespecific markers.

Then, a complete set of wheat-rye disomic and ditelosomic addition lines of 'Holdfast-KingII' and a set of wheat-rye disomic addition lines of 'Chinese SpringImperial' were used for the location and verification of these 667 markers. All of the wheat-rye addition lines were clearly identified to contain the two corresponding rye chromosome arms or chromosomes by GISH and non-denaturing FISH (ND-FISH) analyses, such as the 3RS ditelosomic addition line of 'Holdfast-KingII' identified by the probes of Oligo-pSc119.2-1 and OligopTa535-2 (Fig. 1a and b) and the 1R disomic addition line of 'Chinese Spring-Imperial' identified by the probes of Oligo-pSc119.2-1 and Oligo-pAs1-1 (Fig. 1c and d).

The markers which amplified specific bands in rye cultivar KingII, and only one of wheat-rye disomic addition lines of 'Holdfast-KingII' but not in others were regarded as rye chromosome-specific markers. As a result, 418 markers were located to specific chromosomes of rye, including 43, 58, 49, 74, 64, 62 and 68 markers on rye chromosome 1R, 2R, 3R, 4R, 5R, 6R and 7R, respectively. Subsequently, the assignments of theses markers to individual chromosome arms were determined using KingII, Holdfast, and a set of wheat-rye disomic addition lines and ditelosomic addition lines of 'Holdfast-KingII'. Consequently, 404 markers that amplified specific bands in KingII, one of wheat-rye disomic addition lines and only one of corresponding ditelosomic addition lines of 'Holdfast-KingII' but not in others were obtained. Examples of amplification bands from four specific markers, SW5282 for 1RS, SW252224 for 2RL, SW28002 for 3RS and SW26615 for 6RL, are showed in Fig. 2. Among the 404 rye chromosome arm-specific markers, $7,34,4,53$,

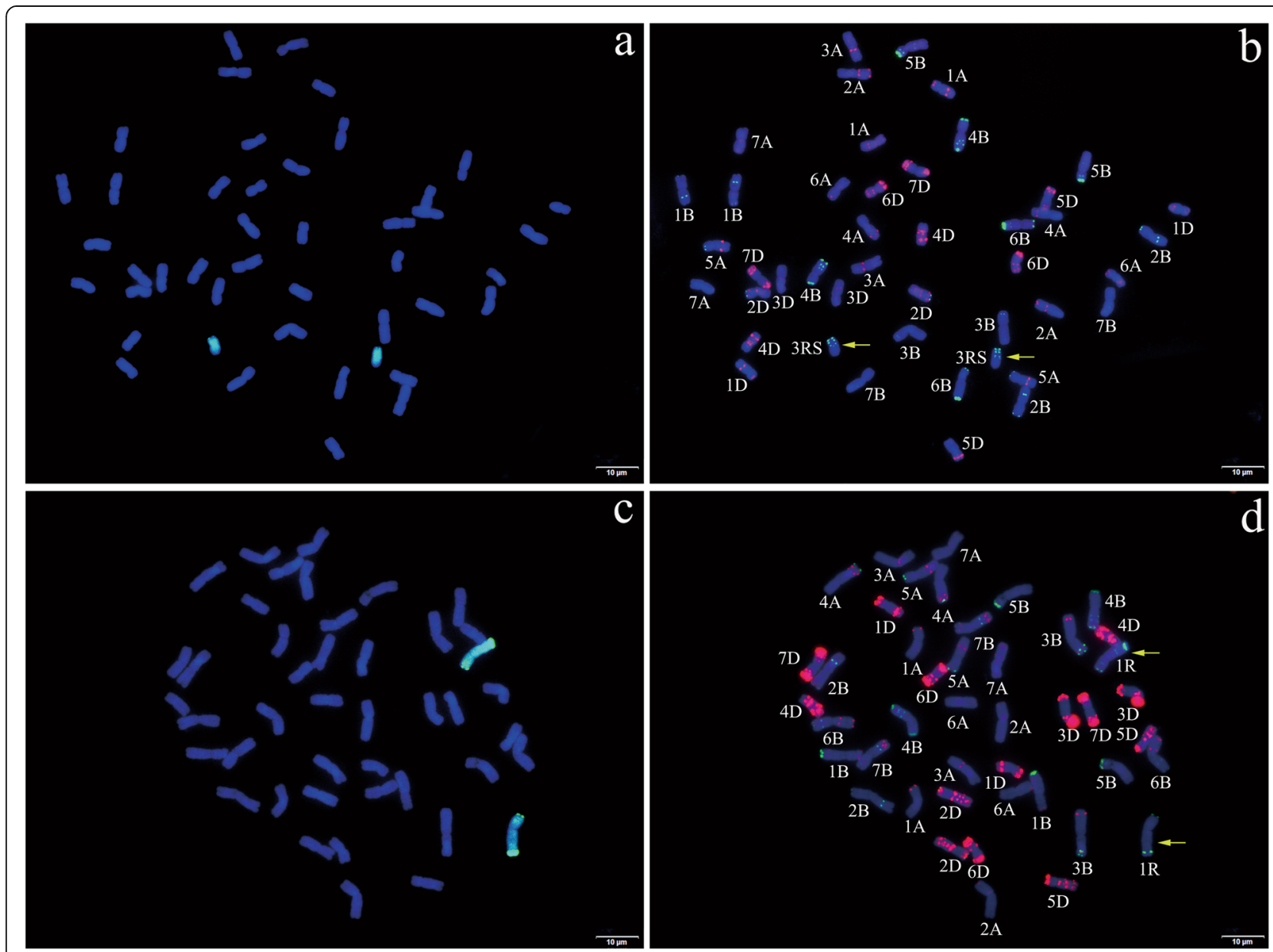

Fig. 1 Genomic in situ hybridization (GISH) and non-denaturing fluorescence in situ hybridization (ND-FISH) analyses of 3RS ditelosomic addition line of 'Holdfast-Kingll' and $1 \mathrm{R}$ disomic addition line of 'Chinese Spring-Imperial'. For GISH, the rye genomic DNA (green) was used as a probe and Chinese Spring DNA as a blocker. Chromosomes were counterstained with DAPI (blue). a GISH analysis of 3RS ditelosomic addition line of 'Holdfast-Kingll'. b ND-FISH analysis of the same metaphase cell after GISH analysis (a) with Oligo-pSc119.2-1 (green) and Oligo-pTa535-2 (red). c GISH analysis of 1R disomic addition line of 'Chinese Spring-Imperial'. d ND-FISH analysis of same metaphase cell with after GISH analysis (c) with Oligo-pSc119.2-1 (green) and Oligo-pAs1-1 (red). The bar represents $10 \mu \mathrm{m}$ and the arrows represent rye chromosomes or chromosome arms 


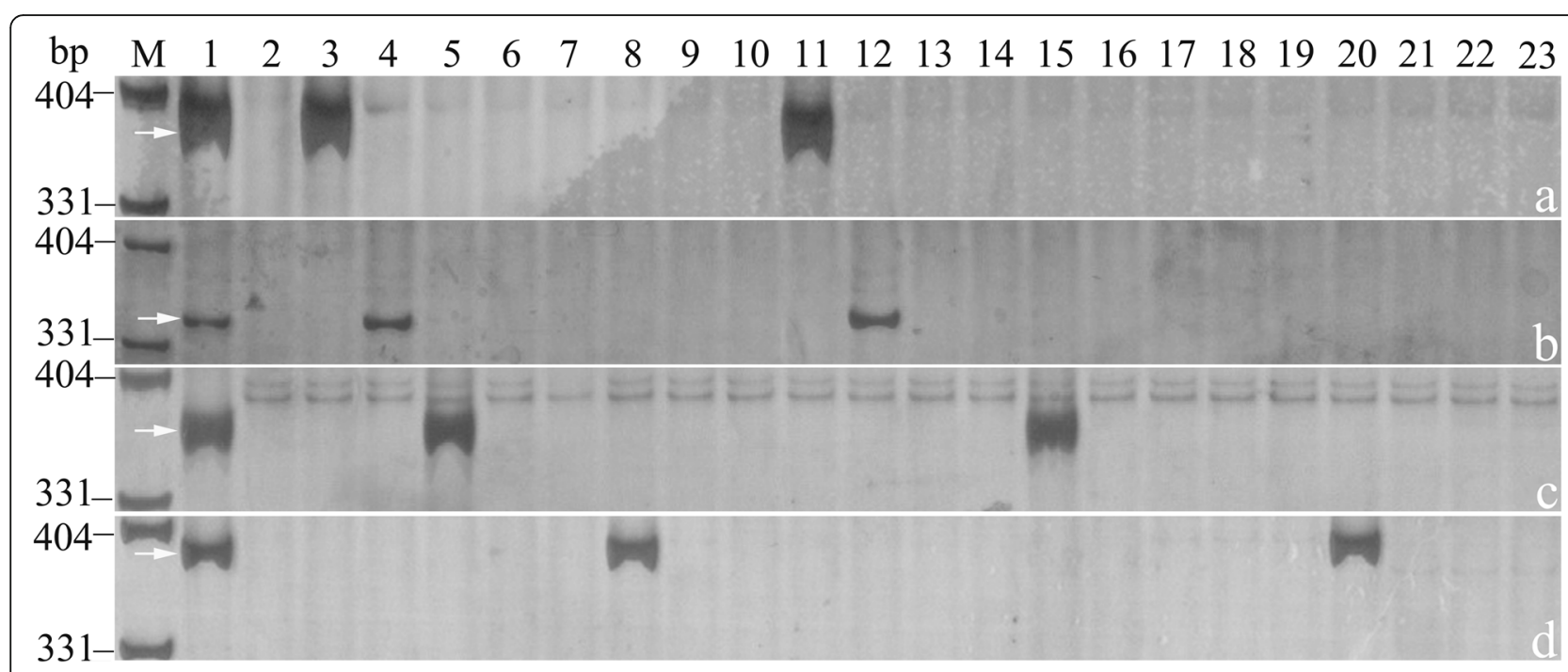

Fig. 2 PCR amplification for location of 1RS-specific marker SW5282, 2RL-specific marker SW252224, 3RS-specific marker SW28002 and 6RL-specific marker SW26615 (a-d) on corresponding rye chromosome arms, respectively. The arrows represent targeted bands. M: pUC19/Mspl, 1: Kingll, 2: Holdfast, 3-9: 1R-7R disomic addition lines of 'Holdfast-Kingll', 10-23: 1RL, 1RS-7RL and 7RS ditelosomic addition lines of 'Holdfast-Kingll'

$23,25,24,50,30,33,16,42,26,37$ markers were successively assigned to $1 R S, 1 R L, 2 R S, 2 R L, 3 R S, 3 R L, 4 R S$, 4RL, 5RS, 5RL, 6RS, 6RL, 7RS and 7RL arms of rye chromosome, respectively (Fig. 3). Each of the markers was referred to individual SLAF, except for the seven and four markers assigned to $1 \mathrm{RS}$ and 2RS, respectively. Only two markers were assigned to each of these two arms initially, but in order to increase the markers available, a total of seven and four markers located on 1RS and 2RS were redesigned based on the sequence of original scaffold of S. cereale L. Lo7 [36] which it belongs to. The primer sequences of these markers are presented in Additional file 1: Table S1.

Then, the 404 markers were valuated their specificity, stability and universality with KingII, Holdfast, Imperial, Chinese Spring, a set of wheat-rye disomic addition lines of 'Chinese Spring-Imperial', wheat-rye lines WR35, WR41, WR49, WR56, and WR91 which involved different rye chromosomes or chromosome arms, T1RS.1BL translocation line Lovrin10, two octoploid triticale lines 09R1-38 and 09R1-100, and wheat cultivar Shixin633. For instance, the 3RS-specific marker SW28002 and 6RL-specific marker SW26615 were successfully validated to amplify the same specific bands in Imperial, corresponding addition line of 'Chinese Spring-Imperial' and two octoploid triticale lines 09R1-38 and 09R1-100 as in KingII. SW26615 also amplified the specific bands in the wheat-rye 6R addition line WR49 (Fig. 4). All of the markers could amplify specific bands in the corresponding wheat-rye addition lines of 'Chinese SpringImperial' and materials. Thus, the specificity, stability and universality of the 404 universal rye chromosome arm-specific PCR-based markers were finally confirmed.
Development and validation of rye specific KASP markers In order to achieve higher efficiency of these markers in MAS, a whole set of KASP markers specific for the 14 individual rye chromosome arms were developed and validated. Firstly, 14 PCR-based markers have already been assigned to the 14 rye chromosome arms were randomly selected to convert to KASP markers. According to the results of sequence alignment, each of the 14 original SLAF sequences could compared to a highly homologous scaffold of S. cereale L. Lo7 [36], indicating the specificity of these SLAFs in rye genome. Subsequently, a large amount of targeted sequences with only one unique SNP between rye and wheat genome [35], derived from the 14 SLAFs or the expanded scaffold sequences of $S$. cereale L. Lo7 [36], respectively, were obtained via SNP calling analyses. KASP markers were designed based on the selected targeted sequences with favorable primer quality. These markers were validated using the following cultivars or lines: 12 rye cultivars including KingII, Imperial, German White, Jingzhouheimai, Baili, Guyuan, CIse 1, CIse 12, CIse14, CIse17, CIse53 and CIse54, a complete set of wheat-rye disomic and ditelosomic addition lines of 'Holdfast-KingII', a set of disomic addition lines of 'Chinese Spring-Imperial', and 11 wheat cultivars including Holdfast, Chinese Spring, Shixin633, Shixin733, Shixin828, Gao8901, Jishi02-1, Shimai15, Kenong199, Heng5471 and Jimai22. Consequently, 14 KASP markers specific for the individual 14 rye chromosome arms were successfully developed (Table 1).

The set of rye chromosome arm-specific KASP markers developed in this study were co-dominant to clearly distinguish three genotypes: two homozygous alleles indicated rye-derived SNPs or wheat-derived SNPs, and 


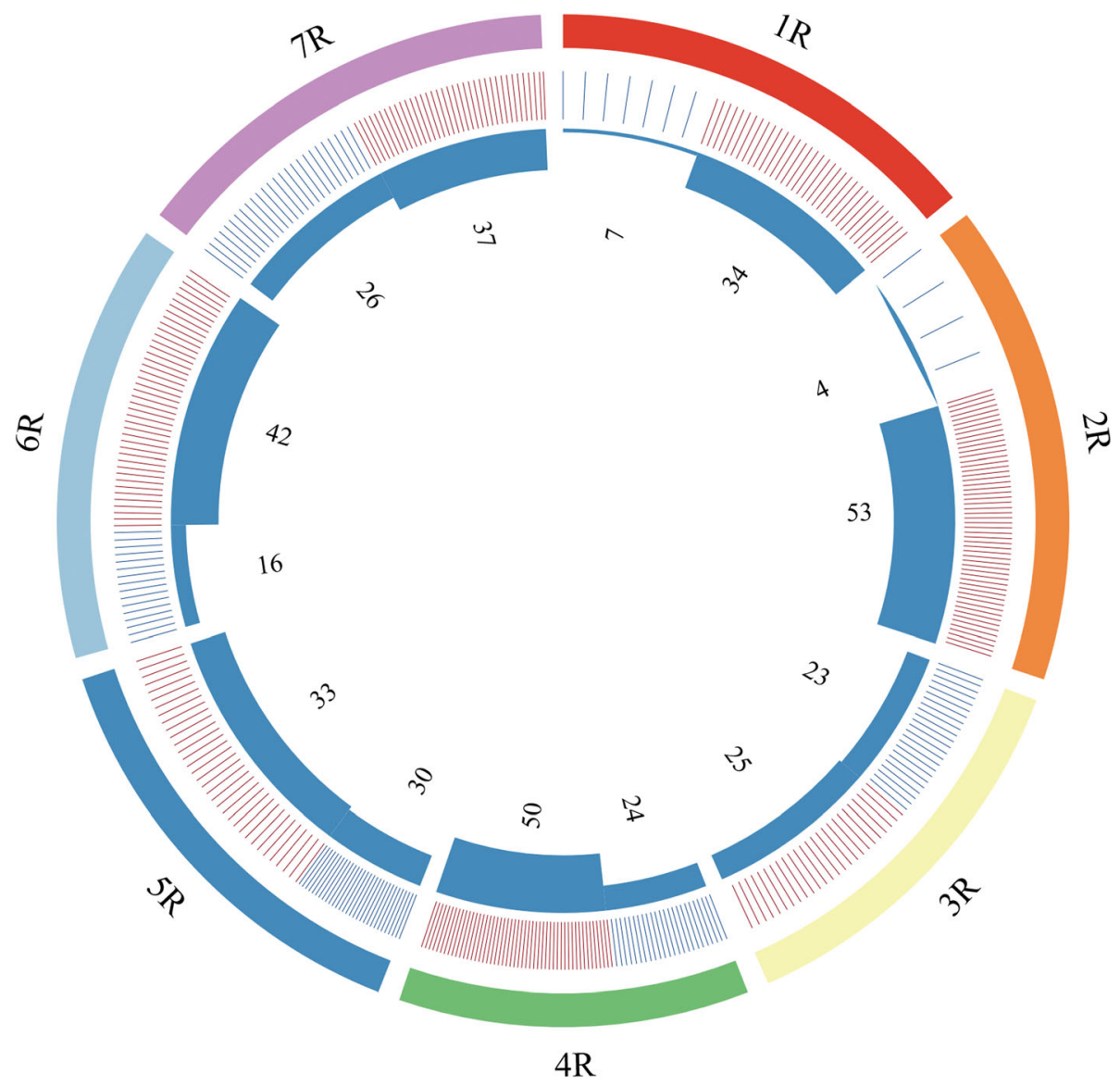

Fig. 3 Frequency and number of the markers assigned to the individual rye chromosome arms. The outer track is separated to seven circular tracks showing the seven chromosomes $1 R$ to $7 R$ of rye. The second track is formed by blue bars and red bars which indicate markers assigned to short arm and long arm, respectively. The density of the bars illustrates the frequency of the markers assigned to the individual rye chromosome arms. The inner blue blocks present the number of the markers located on the individual rye chromosome arms

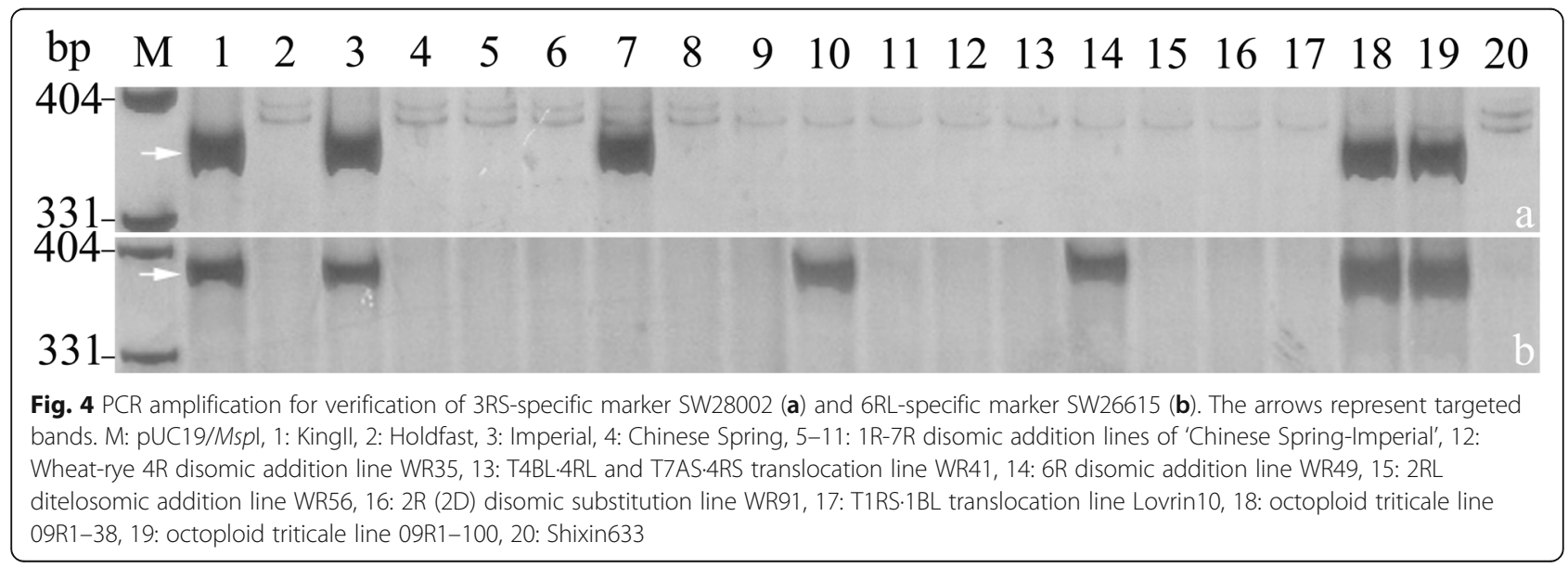


Table 1 Primer sequences of Kompetitive allele-specific PCR (KASP) markers specific for 14 rye chromosome arms

\begin{tabular}{|c|c|c|}
\hline KASP marker & Location & Primer sequences $\left(5^{\prime}-3^{\prime}\right)$ \\
\hline SWK5282-F & 1RS & gaaggtgaccaagttcatgctGAGCTGATTTCCATGTA \\
\hline SWK5282-H & & gaaggtcggagtcaacggattGAGCTGATTTCCATGTC \\
\hline SWK5282-C & & TACCAAGTCCTGAACCA \\
\hline SWK23822-F & $1 \mathrm{RL}$ & gaaggtgaccaagttcatgctTATGGGAATTTATGGCCGCA \\
\hline SWK23822-H & & gaaggtcggagtcaacggattTATGGGAATTATGGCCGCG \\
\hline SWK23822-C & & CCCGGAAAAGCTCCTTTT \\
\hline SWK621-F & $2 \mathrm{RS}$ & gaaggtgaccaagttcatgctGAGGAAGCTCCATCAATCTG \\
\hline SWK621-H & & gaaggtcggagtcaacggattGAGGAAGCTCCATCAATCTT \\
\hline SWK621-C & & CACCGAATCAATCATGCAAC \\
\hline SWK252224-F & $2 R L$ & gaaggtgaccaagttcatgctTCAACACCAAGAGAAGGGAAC \\
\hline SWK252224-H & & gaaggtcggagtcaacggattTCAACACCAAGAGAAGGGAAA \\
\hline SWK252224-C & & CAGATGCATGTAGGTAGCGC \\
\hline SWK28002-F & $3 R S$ & gaaggtgaccaagttcatgctCGGACAATGCACGATCGA \\
\hline SWK28002-H & & gaaggtcggagtcaacggattCGGACAATGCACGATCGG \\
\hline SWK28002-C & & CGCACGCACATCAACACG \\
\hline SWK15063-F & $3 R L$ & gaaggtgaccaagttcatgctCGAAAGTATGGGCTGCATTाT \\
\hline SWK15063-H & & gaaggtcggagtcaacggattCGAAAGTATGGGCTGCATTC \\
\hline SWK15063-C & & CCGACCCGTTCAGCCATT \\
\hline SWK30487-F & 4RS & gaaggtgaccaagttcatgctGGGTCGAGGTAGGTGAGG \\
\hline SWK30487-H & & gaaggtcggagtcaacggattGGGTCGAGGTAGGTGAGC \\
\hline SWK30487-C & & GCTGACGGCACAATCAAC \\
\hline SWK61253-F & $4 \mathrm{RL}$ & gaaggtgaccaagttcatgctTGAAGTACTCAGCATTCAGC \\
\hline SWK61253-H & & gaaggtcggagtcaacggattTGAAGTACTCAGCATTCAGT \\
\hline SWK61253-C & & GTTCTCTTGTTCACACTCCAGT \\
\hline SWK190654-F & $5 \mathrm{RS}$ & gaaggtgaccaagttcatgctAGGCCAAGAGAAGAGTGAAGAC \\
\hline SWK190654-H & & gaaggtcggagtcaacggattAGGCCAAGAGAAGAGTGAAGAT \\
\hline SWK190654-C & & TAACTACCGGCTGCCCTIIT \\
\hline SWK37355-F & $5 R L$ & gaaggtgaccaagttcatgctTTCTGGTCCTAACGCTGAA \\
\hline SWK37355-H & & gaaggtcggagtcaacggattTTCTGGTCCTAACGCTGAG \\
\hline SWK37355-C & & CTGCATGCAATTCAAGACAGA \\
\hline SWK38534-F & $6 \mathrm{RS}$ & gaaggtgaccaagttcatgctTGAATCTCAACCATGCCCTT \\
\hline SWK38534-H & & gaaggtcggagtcaacggattTGAATCTCAACCATGCCCTC \\
\hline SWK38534-C & & CCTTGACTGTGTGGCCGATT \\
\hline SWK26615-F & $6 \mathrm{RL}$ & gaaggtgaccaagttcatgctCACTTAACTTGGCGTTGGAG \\
\hline SWK26615-H & & gaaggtcggagtcaacggattCACTITAACTTGGCGTTGGAC \\
\hline SWK26615-C & & CTGAACTGGCCATTTGCA \\
\hline SWK31799-F & 7RS & gaaggtgaccaagttcatgctACCTGAATATTGGGCGCA \\
\hline SWK31799-H & & gaaggtcggagtcaacggattACCTGAATATTGGGCGCC \\
\hline SWK31799-C & & TCACAGATCAACCTAGCCTCC \\
\hline SWK13002-F & $7 R L$ & gaaggtgaccaagttcatgctATGCTTCTGCTGGTCTCTT \\
\hline SWK13002-H & & gaaggtcggagtcaacggattATGCTTCTGCTGGTCTCTC \\
\hline SWK13002-C & & CCAATACAGGAGTAGATCGAC \\
\hline
\end{tabular}


heterozygous alleles indicated presence of both wheatderived and rye-derived SNPs. The genotyping results of 3RS-specific KASP marker SWK28002 and 6RL-specific KASP marker SWK26615 are distinctly shown in Fig. 5.

\section{Application of rye specific KASP markers}

Using the 1RS-specific KASP marker SWK5282, the detection of $1 R S$ translocations in a natural population with 161 wheat cultivars/lines was clearly and intuitively displayed (Fig. 6a). The distribution of 1RS translocations in
161 wheat cultivars/lines were also confirmed by the corresponding PCR-based marker SW5282 (Fig. 7). The results indicated that 78 of 161 wheat cultivars/lines contained 1RS translocations, which were consistent with the results of PCR-based marker SW5282, also provided guidance to use 1RS translocation lines in MAS breeding for wheat breeders (Additional file 2: Table S2).

WR91 was a wheat-rye 2R (2D) substitution line which was previously confirmed to exhibit adult resistance to powdery mildew on 2RL chromosome. To further transfer

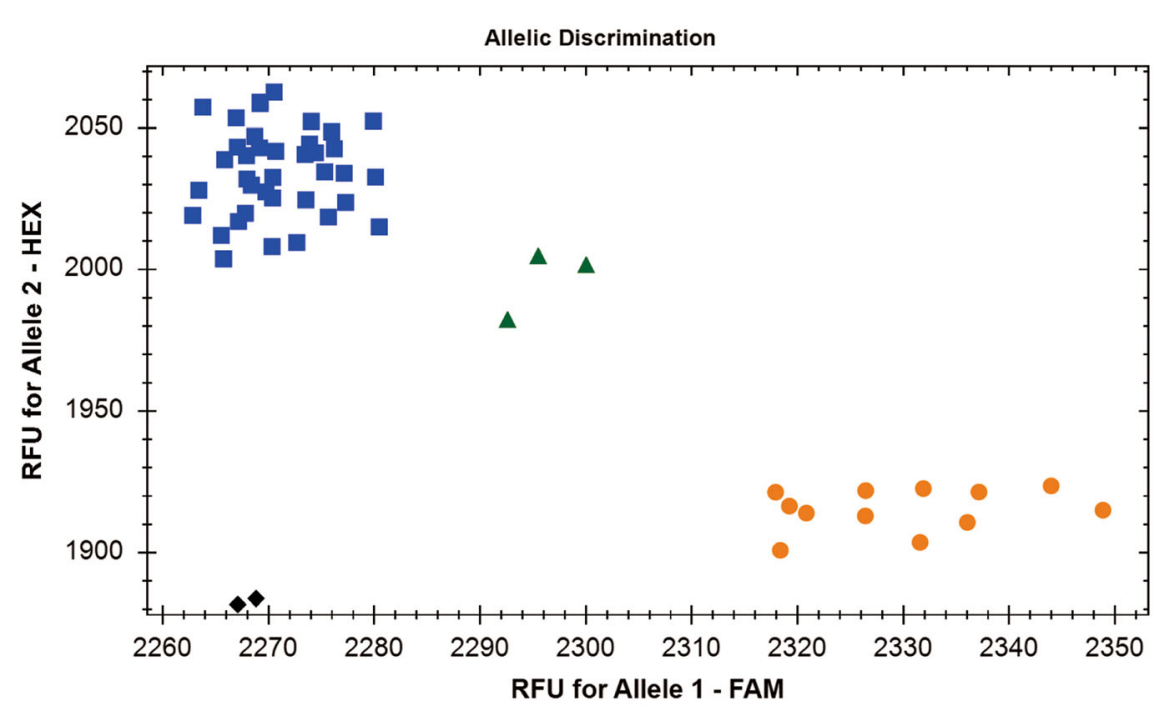

a

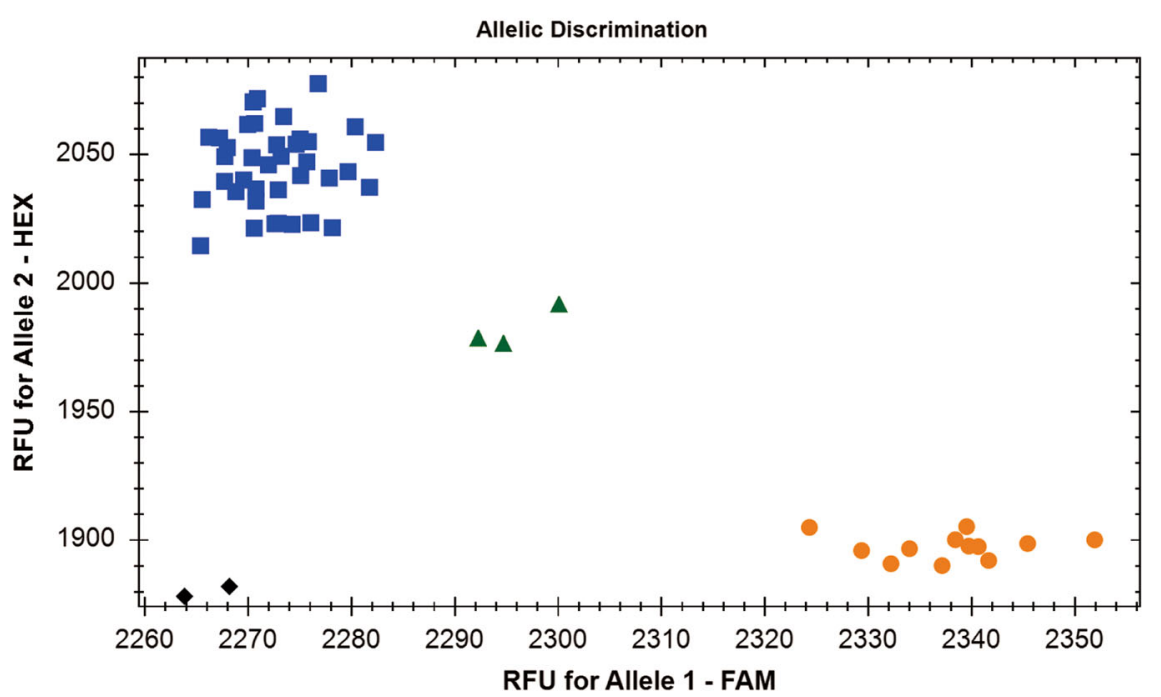

b

. Genotyping results of 3RS-specific Kompetitive allele-specific PCR (KASP) Marker SWK28002 (a) and 6RL-specific KASP Marker SWK26615 (b). Orange rotund shapes that represent homozygous rye-derived specific SNP 'Allele1/Allele1' indicate 12 rye cultivars including Kingll, German White, Imperial, Jingzhouheimai, Baili, Guyuan, Clse 1, Clse 12, Clse14, Clse17, Clse53 and Clse54; blue square shapes that represent homozygous wheat-derived specific SNP 'Allele2/Allele2' indicate two sets of disomic addition lines of 'Holdfast-Kingll' and 'Chinese Spring-Imperial' without 3R/6R disomic addition lines, a set of ditelosomic addition lines of 'Holdfast-Kingll' without 3RS/6RL ditelosomic addition line, and 11 wheat materials including Holdfast, Chinese Spring, Shixin633, Shixin733, Shixin828, Ga08901, Jishi02-1, Shimai15, Kenong199, Heng5471 and Jimai22; and green triangle shapes that represent heterozygous rye- and wheat- derived SNP 'Allele1/Allele2' indicate 3R/6R disomic addition line and 3RS/6RL ditelosomic addition line of 'Holdfast-Kingll' and 3R/6R disomic addition line of 'Chinese Spring-Imperial'. Black diamond shapes indicate no template control 


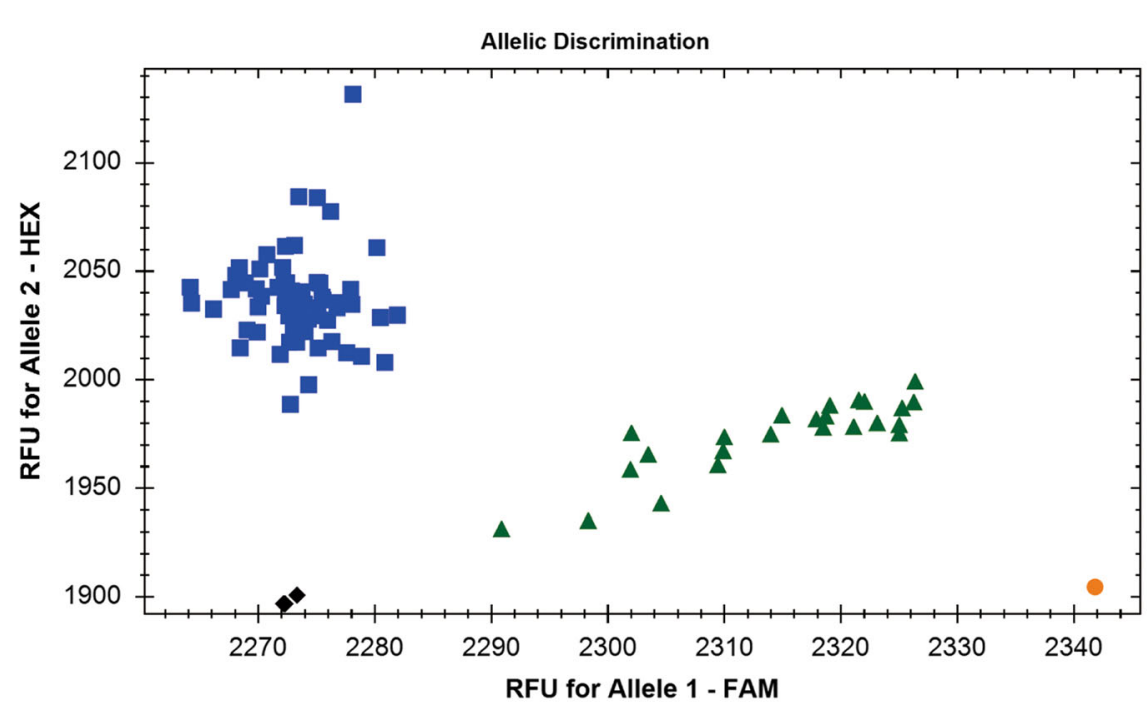

a

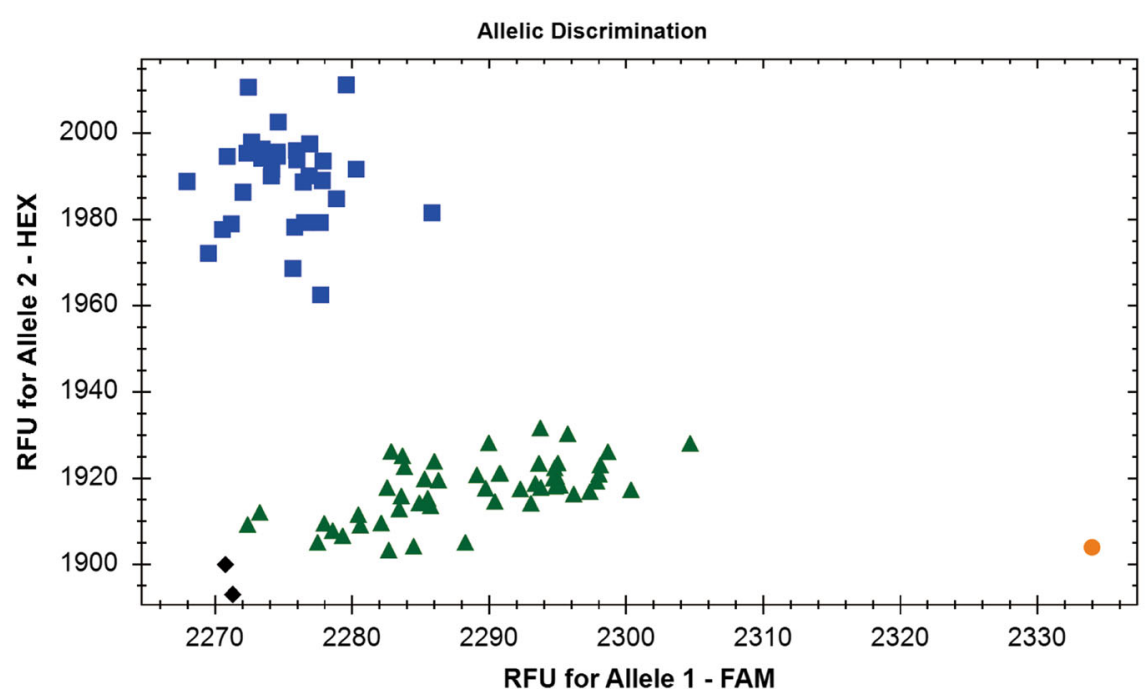

Fig. 6 Application of 1RS-specific Kompetitive allele-specific PCR (KASP) marker SWK5282 and 2RL-specific KASP marker SWK252224. a Using the 1RS-specific KASP marker SWK5282, the partial genotyping results of 1RS translocation lines in 161 wheat cultivars/lines were displayed. Orange rotund shape represents the homozygous 1RS special SNP ('Allele1/Allele1') indicating rye Imperial, blue square shapes represent the homozygous wheat special SNP ('Allele2/Allele2') indicating Chinese Spring and the wheat culitivars/lines without 1RS translocations, and green triangle shapes represent the presence of both Allele1 and Allele2 indicating the wheat cultivars/lines containing 1RS translocations. Black diamond shapes indicate no template control. b Using the 2RL-specific KASP marker SWK252224, 2RL chromosomes in $81 \mathrm{~F}_{2}$ individuals of WR91 and Shixin633 were identified. Orange rotund shape represents the homozygous 2RL special SNP ('Allele1/Allele1') indicating rye Imperial, blue square shapes represent the homozygous wheat special SNP ('Allele2/Allele2') indicating Chinese Spring and $F_{2}$ individuals without 2RL chromosome, and green triangle shapes represent the presence of both Allele1 and Allele2 indicating $F_{2}$ individuals containing $2 R L$ chromosome. Black diamond shapes indicate no template control

the resistance into susceptible commercial cultivar, WR91 has been crossed with Shixin633 and generated $F_{2}$ populations. The 2RL-specific KASP marker SWK252224 was used to rapidly detect the 2RL chromosomes. Among the tested $81 \mathrm{~F}_{2}$ individuals, 50 individuals as shown in green triangle shapes were resistant to powdery mildew at adult stage with infection types $0-2$, whereas the other 31 individuals as shown in blue square shapes were susceptible with infection types 7-9 (Fig. 6b). In addition, the detection results of KASP marker SWK252224 were identical to those of the corresponding PCR-based marker SW252224. The application of the KASP marker SWK252224 will greatly facilitated the detection and transfer of 2RL chromosome into wheat background.

\section{Discussion}

Rye is an important gene donor for disease resistance, superior agronomic traits and environment adaptation 


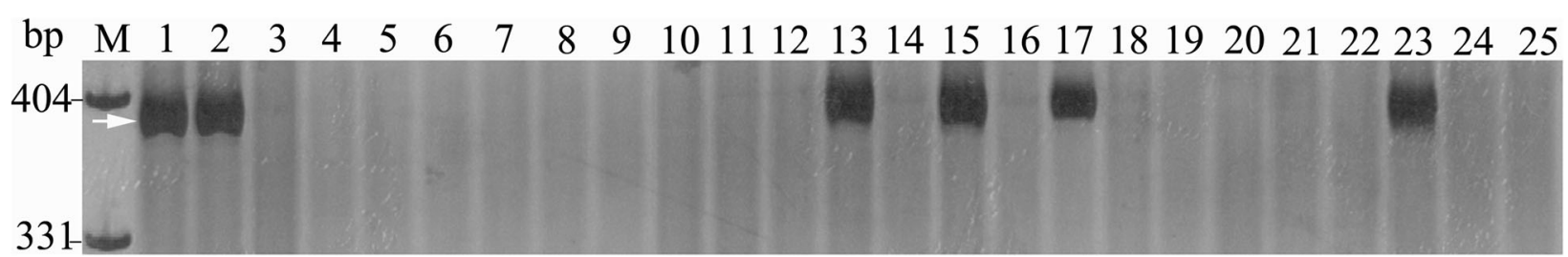

Fig. 7 PCR amplification of 1RS-specific PCR-based marker SW5282 for the detection of 1RS translocations in part of 161 wheat cultivars/lines. M: pUC19/Mspl, 1: Imperial, 2: Lumai5, 3: Luami13, 4: Lumai23, 5: Liangxing66, 6: Liangxing99, 7: Jimai19, 8: Jimai20, 9: Jimai22, 10: Jinan17, 11: Tainong18, 12: Tainong19, 13: Jinan16, 14: Shannong17, 15: Luyuan502, 16: Shannong21, 17: DH5197, 18: Wennong14, 19: Lumai21, 20: Yannong19, 21: Yannong21, 22: Yannong23, 23: Weimai8, 24: Yannong24, 25: Jimai21

in wheat breeding. A great number of desirable wheatrye progenies from various rye accession have been developed by distant hybridization and chromosome engineering, such as wheat-rye $6 \mathrm{R}$ disomic addition line WR49 carrying powdery mildew resistance derived from rye cultivar German White [37], wheat-rye 1R disomic addition line N9436B carrying powdery mildew resistance derived from rye cultivar Austrian [38], and wheatrye T1RS.1BL translocation lines from Chinese rye cultivar Baili with resistances to stripe rust and powdery mildew and desirable agronomic traits [39]. Compared with addition lines and substitution lines, translocation lines, especially small segment translocation lines carrying desirable traits, are preferred attributing to less linkage drag. Therefore, more wheat-rye introgression lines with small segments have been induced and produced [40, 41]. In this case, development of high-density ryespecific molecular markers is necessary and urgent. Besides, rye has strong heterogeneity. Guo et al. [42] identified 300 individuals from six open-pollinated rye cultivars, while no identical karyotypes were found among these individuals. This demonstrated that some rye chromosome-specific markers are not able to identify a given chromosome across all rye cultivars. In most of the previous studies, researchers usually developed rye-specific markers basing on the obtained sequences from one kind of rye cultivar or only used one set of wheat-rye addition lines to assign them, without confirming their universality in many other rye cultivars [24, $25,43-45]$. In the present study, a total of 404 PCRbased rye chromosome-specific markers were developed based on the conserved sequence across the five rye cultivars and verified with the sixth rye cultivar KingII. Meanwhile, two sets of wheat-rye addition lines were used to assign the markers to individual chromosomes. Thus, theses markers were supposed to be more universal, enable the identification of alien chromatin of various rye cultivars, and provide powerful tools for constructing map of rye and MAS.

Previously, developing markers was low-efficient due to the lack of genome reference information of the wheat relatives. SLAF-seq is an efficient next-generation sequencing method that can rapidly obtain a large amount of high-quality enzymatic fragments [46]. Therefore, SLAF-seq can be effectively applied to development of alien chromosome specific markers [47, 48]. In the present study, 418 markers derived from 1546 SLAFs were assigned to rye chromosomes, and finally 404 markers were assigned to universal chromosome arms, with a success rate of up to $26 \%$. In addition, the frequency of markers located on most of chromosome arms was relatively uniform, except for the fewer markers on chromosome arms 1 RS and 2RS, which was probably caused by fewer distribution of the selected restriction fragments on these two arms. All these PCRbased markers were used easily to trace the rye chromosome segments in wheat background.

Recent advances in NGS promoted the construction of reference sequence assemblies and development of highdensity DNA genotyping platforms for crops. Winfield et al. [49] developed high-density SNP genotyping array for hexaploid wheat and its secondary and tertiary gene pool based on exome capture and NGS, which can achieve the tracking of the introgression and subsequent fate of chromosomal segments from wheat relatives in wheat breeding. A Wheat-Relative SNP Genotyping Array has also been developed and used to identify the wild relative introgressions in a wheat background [5053]. However, these SNP genotyping platforms are limited in practical breeding due to their inflexibility in assay design, identification and costly equipment for application, although they are high-throughput and highefficient [54]. With the help of the published sequencing data of wheat, KASP marker has been widely used in mapping and MAS due to its advantages of high throughput, high flexibility, good genetic stability, locus specificity and low cost $[31,55]$. Compared with common wheat, the lack of high-quality whole genome sequencing information of wheat relatives limits the development of alien specific KASP markers and its utilization in MAS. Tiwari et al. [56] developed KASP markers for detecting $5 \mathrm{M}^{\mathrm{g}}$ segments in wheat-Aegilops geniculate introgression lines by combining chromosome flow-sorting and next-generation sequencing technology, 
while the flow-sorting technology is expensive and not yet widespread. Rahmatov et al. [17] developed three 2RL-specific KASP markers with two genotypes: lines with targeted segment displayed the rye allele, whereas the lines without targeted segments displayed null allele. Ma et al. [34] developed the co-dominant KASP markers that were able to detect Agropyron cristatum chromosome based on the RNA-seq data. Recently, Grewal et al. [57] developed chromosome-specific KASP genotyping assays for ten wild relative species based on the probe sequences on the Axiom ${ }^{\circ}$ Wheat-Relative Genotyping Array. These markers that have been developed will provide powerful tools for wheat breeders worldwide.

Compared with the reported studies, the strategy of developing alien specific KASP markers in this study was low-cost and high-efficient. In this study, 14 specific markers distributed on the 14 arms were selected and finally a whole set of rye chromosomal arm-specific KASP markers were developed and valuated. Firstly, SLAF-seq was used to develop PCR-based markers. Subsequently, the original SLAF sequences of the specific markers or the expanded sequences obtained by the S. cereale $\mathrm{L}$. Lo7 scaffolds database [36] were compared with the Chinese Spring reference sequences [35] to search the single unique SNP. Finally, the specific KASP markers were developed based on the targeted SNP. Actually, the results of sequence alignment with the data of $S$. cereale L. Lo7 scaffolds [36] have proved that the PCR-based specific markers obtained in the first step could largely ensure the sequence specificity and accuracy. For the second step, the reference genome sequencing information of the wheat relatives are not necessary if the specific SLAFs on targeted chromosomes are enough. Therefore, this strategy can be a good reference for other wheat relatives.

The whole set of 14 rye chromosome arm-specific KASP markers could clearly distinguish three genotypes for wheat, rye, and wheat-rye introgression. Meanwhile, the targeted single unique SNPs with wheat were sequenced to be conserved among five rye cultivars as well it was turned out in six other rye cultivars, indicating the universality of these KASP markers in various rye cultivars. For the detection of 1RS translocations in a natural population with 161 wheat cultivars/lines, SWK5282 was more time-saving and convenient than PCR-based marker SW5282. The result also demonstrated that this KASP marker can be applied to screen wheat-rye derived populations on large scale, unconstrained by different wheat and rye backgrounds. In addition, the introduction of $1 \mathrm{RS}$ arms into common wheat leads to defects in bread-making quality while improving yield [58], the detection results in this study thereby provide guidance for parent selection in wheat breeding. For the tracing of the powdery mildew resistance derived from chromosome 2RL, the cosegregation of the resistance phenotype with KASP marker SWK252224 indicated that this marker could be used in high-throughput detection of 2RL chromosome in wheat-rye derived populations, significantly accelerating the transfer of resistance genes into susceptible wheat cultivars. Recently, two 4RL-specific markers have been successfully developed and applied in MAS using this strategy in our lab [59]. Actually, many valuable alien genes were transferred into wheat mainly in forms of stable Robertsonian translocations, such as wheatDasypyrum villosum translocation line T6VS.6AL harboring Pm21 [60] and wheat-barley group-7 Robertsonian translocation lines conferring an increased content of $\beta$-glucan [61]. Hence, the developed KASP markers specific for rye chromosome arms can be considered as co-segregation markers with valuable traits and widely used in large-scale MAS.

\section{Conclusions}

Based on SLAF-seq and bioinformatics analyses, a total of 404 universal rye chromosome arm-specific PCRbased markers and a set of KASP markers were developed and validated. These markers can enrich the ryespecific markers and accelerate the large-scale screening of various rye germplasm resources and highthroughput detection of rye chromatin in wheat background. Two KASP markers specific for 1RS and 2RL were successfully applied in the detection of 1RS translocations in a natural population and 2RL chromosome arms that conferred resistance to powdery mildew. In addition, the present study provided an efficient strategy for wheat relatives to develop specific KASP markers, which would improve the efficiency of genetic studies and MAS for alien chromosome engineering breeding.

\section{Methods \\ Plant materials}

Five rye cultivars including Imperial, German White, Jingzhouheimai, Baili and Guyuan were sequenced by SLAF-seq to develop rye chromosome arm-specific markers. Rye cultivar Baili, wheat cultivar Holdfast, and a complete set of wheat-rye disomic addition lines of 'Holdfast-KingII' were kindly provided by Dr. Zongxiang Tang (Sichuan Agricultural University, Chengdu, CHN). Rye cultivar Imperial and a complete set of wheat-rye disomic addition lines of 'Chinese Spring-Imperial' were kindly provided by Dr. John Raupp (Kansas State University, Manhattan, U.S.). Rye cultivar Jingzhouheimai was kindly provided by Dr. Lifang Zhuang (Nanjing Agricultural University, Nanjing, CHN). A complete set of ditelosomic addition lines of 'Holdfast-KingII' were kindly provided by Dr. Adrian Turner (John Innes Centre, Norwich, UK). Rye cultivars KingII, CIse 1, CIse 12, CIse14, 
CIse17, CIse53 and CIse54 were kindly provided by Dr. Yiwen Li (Institute of Genetics and Developmental Biology, Chinese Academy of Sciences, Beijing, CHN).

The following materials maintained in our laboratory including wheat cultivars Chinese Spring, Shixin633, Shixin733, Shixin828, Gao8901, Jishi02-1, Shimai15, Kenong199, Heng5471 and Jimai22, two octoploid triticale lines $(2 \mathrm{n}=56$, AABBDDRR) 09R1-38 and 09R1100, and a wheat-rye T1RS.1BL translocation line Lovrin10, were used for the location and verification of rye chromosome arm-specific markers. The wheat-rye lines used for the verification also included wheat-rye $4 \mathrm{R} \mathrm{di-}$ somic addition line WR35, T4BL-4RL and T7AS.4RS translocation line WR41, 6R disomic addition line WR49, 2RL ditelosomic addition line WR56 and 2R (2D) disomic substitution line WR91, all these lines were developed from 'Xiaoyan $6 \times$ German White', and previously identified by using GISH and mc-FISH analyses [20].

One hundred and sixty-one wheat cultivars/lines maintained in our laboratory and the $\mathrm{F}_{2}$ individuals derived from the cross of WR91 and Shixin633 susceptible to powdery mildew were used to validate the practical utilization of the rye chromosome arm-specific KASP markers. The wheat cultivar Mingxian169 without Pm genes that maintained in our laboratory was used as susceptible control in assessment of reaction to powdery mildew at the adult stage. All the seedlings were used for extracting total genomic DNA by the CTAB method [62]. Genomic DNA of Chinese Spring was used as a blocking DNA in GISH detection.

\section{SLAF sequencing, sequence comparison and rye-specific fragment acquisition}

Genomic DNA samples of rye cultivars Imperial, German White, Jingzhouheimai, Baili and Guyuan were, respectively, sequenced by SLAF-seq (Biomarker, Beijing, China) as previously described with some modifications [63]. Firstly, the above five genomic DNA samples were digested with the restriction enzyme RsaI, respectively. Secondly, a single-nucleotide overhang was added to the digested fragments and the duplex tag-labeled sequencing adapters were ligated to the A-tailed DNA with T4 DNA ligase. Thirdly, the PCR amplified products were purified and electrophoresed on a $2 \%$ agarose gel to isolate the fragments with 464-494 bp in size which were subsequently excised and purified. Finally, the purified products were sequenced on the Illumina HiSeq 2500 sequencing platform (Illumina, Inc., San Diego, CA, USA).

All SLAF pair-end reads generated from SLAF-seq raw reads were filtered according to the quality, and then highquality clean reads with over $90 \%$ identity were clustered into one SLAF locus. In order to obtain the rye-specific fragments, all the SLAFs derived from the five rye cultivars were compared with the wheat genome using BWA software [64], leaving the SLAFs with low identity less than $50 \%$. The comparison among respective remaining SLAFs from the five rye cultivars were also carried out to finally acquire the conserved rye-specific sequences.

\section{Sequential GISH and non-denaturing FISH analyses}

GISH analyses were performed to confirm the existence of the rye chromosomes or chromosome arms in the complete set of wheat-rye disomic and ditelosomic addition lines of 'Holdfast-KingII' and a set of disomic addition lines of 'Chinese Spring-Imperial'. The root tip cells were prepared for mitotic chromosome observation and hybridization as previously described [65]. Total genomic DNA of rye cultivar KingII or Imperial was labeled with fluorescein-12-dUTP (green) by nick translation method and used as a probe, while genomic DNA of Chinese Spring was used as blocker with the ratio of probe/blocker on 1:50. After GISH analyses, ND-FISH analyses were conducted to determine the identity of the rye and wheat chromosomes by using two combinations of oligonucleotide probes, respectively. The probe OligopSc119.2-1 (green) was 5' end-labeled with 6carboxyfluorescein (FAM) and the probes Oligo-pAs1-1 (red) and Oligo-pTa535-2 (red) were 5'end-labeled with 6-carboxytetramethylrhodamine (TAMRA). These oligonucleotide probes were synthesized by Shanghai Invitrogen Biotechnology Co. Ltd. (Shanghai, China). The combination of probes Oligo-pSc119.2-1 with OligopAs1-1 or Oligo-pTa535-2 could discriminate all rye chromosomes and 42 common wheat chromosomes. ND-FISH analyses were carried out according to the method as previously described [66]. Then, detection and visualization of rye chromatin were performed through an epifluorescence Olympus BX53 with a cooled CCD digital camera. Program CellSens Standard 1.12 (Olympus Corporation, Tokyo, Japan) was used in images analysis.

\section{Development and verification of rye specific PCR-based markers}

According to the obtained conserved rye-specific sequences, PCR primers were designed using Primer 3 software (http://www.primer3plus.com/primer3web/) for the amplification of five rye cultivars Imperial, German White, Jingzhouheimai, Baili, Guyuan and wheat cultivar Holdfast. All the primers were synthesized by Shanghai Sangon Bio-technology Co., Ltd. (Shanghai, China). Three steps of PCR analysis were performed to develop rye-specific markers: firstly, those markers whose specific band absented in Holdfast but presented in all the six rye cultivars were considered as universal rye-specific markers. Secondly, a set of wheat-rye disomic addition lines of 'Holdfast-KingII' were used to assign the markers to individual rye chromosomes. Finally, a set of 
wheat-rye ditelosomic addition lines of 'Holdfast-KingII' were used to locate the rye chromosome-specific markers onto rye chromosome arms. The frequency and number of markers assigned to the individual chromosome arms were showed in a circos plot drawn by the Circos-0.69-9 software [67].

Additionally, KingII, Holdfast, Imperial, Chinese Spring, a set of wheat-rye disomic addition lines of 'Chinese Spring-Imperial', wheat-rye lines WR35, WR41, WR49, WR56, WR91, Lovrin10, octoploid triticale lines 09R1-38 and 09R1-100, and wheat cultivar Shixin633 were used for testing the specificity of these markers.

The PCR amplification system (10 $\mu$ l total) contains $1 \mu \mathrm{l}$ of template DNA $(100 \mathrm{ng} / \mu \mathrm{l}), 4 \mu \mathrm{l} 2 \times$ Taq Master Mix (Vazyme Biological, Nanjing, China), $4 \mu \mathrm{l} d \mathrm{dd}_{2} \mathrm{O}$ and $1 \mu \mathrm{l}$ primers $(10 \mu \mathrm{mol})$. The PCR procedure was as follow: $94{ }^{\circ} \mathrm{C}$ for $5 \mathrm{~min}$, followed by 36 cycles of $94{ }^{\circ} \mathrm{C}$ for $30 \mathrm{~s}, 58^{\circ} \mathrm{C}$ for $30 \mathrm{~s}, 72{ }^{\circ} \mathrm{C}$ for $40 \mathrm{~s}$, and a final extension at $72{ }^{\circ} \mathrm{C}$ for $10 \mathrm{~min}$. The PCR products were separated in $8 \%$ non-denaturing polyacrylamide gels with 29:1 ratio of acrylamide and bis-acrylamide, and silver-stained prior to visualizing the banding patterns [68].

\section{Development and validation of corresponding KASP markers}

The PCR-based markers specific for rye chromosome arms were analyzed to convert to KASP markers. Firstly, the sequence alignment of the original SLAF sequence with the data of S. cereale L. Lo7 scaffolds [36] was conducted to ensure the specificity of these SLAFs in rye genome. Then, the specific SNPs between original SLAFs or the expanded sequences and wheat were called by MUMmer 3.23 software. The $40-120$ bp sequences with high consistency to wheat genome flanking SNPs were extracted and further evaluated the primer quality to design KASP markers. The KASP markers were designed using Primer 3 software (http://www.primer3plus. $\mathrm{com} /$ primer3web/). The wheat sequences were referred to the IWGSC Ref Seq v1.0 [35].

Subsequently, these KASP markers were validated their specificity, stability, and universality by testing 12 rye cultivars including KingII, Imperial, German White, Jingzhouheimai, Baili, Guyuan, CIse 1, CIse 12, CIse14, CIse17, CIse53 and CIse54, a complete set of wheat-rye disomic and ditelosomic addition lines of 'Holdfast-KingII', a set of disomic addition lines of 'Chinese Spring-Imperial', and eleven wheat cultivars including Holdfast, Chinese Spring, Shixin633, Shixin733, Shixin828, Gao8901, Jishi02-1, Shimai15, Kenong199, Heng5471 and Jimai22.

The KASP amplification system ( $8 \mu$ l total) contains $4.5 \mu \mathrm{l}$ high rox KASP master mix, $0.13 \mu$ l Assay mix,

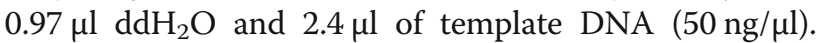
The reaction was performed in a Bio-Rad CFX real-time PCR system (Bio-Rad Laboratories, Inc. California,
USA), PCR procedure was as follow: $94{ }^{\circ} \mathrm{C}$ for $15 \mathrm{~min}$, $94{ }^{\circ} \mathrm{C}$ for $20 \mathrm{~s}$, followed by 10 touchdown cycles of 64 to $58^{\circ} \mathrm{C}$ (decreasing $0.6^{\circ} \mathrm{C}$ per cycle), 38 cycles of $94{ }^{\circ} \mathrm{C}$ for $20 \mathrm{~s}, 58^{\circ} \mathrm{C}$ for $60 \mathrm{~s}$, and fluorescence was detected using Bio-Rad CFX Manage 3.1 software.

\section{Assessment of reaction to powdery mildew at the adult stage}

A wheat-rye 2R (2D) substitution line WR91, derived from 'Xiaoyan $6 \times$ German White', was previously confirmed to confer the adult resistance to powdery mildew that was located on the chromosome arm 2RL. To further transfer the resistance into susceptible wheat cultivar, WR91 has been crossed with Shixin633 and generated $F_{2}$ seeds. WR91, Shixin633 and their $F_{2}$ seeds were planted in early October at the Luancheng Agro-Ecological Experimental Station, Chinese Academy of Sciences, Shijiazhuang, China. Twenty plants were grown in each $1.5-\mathrm{m}$ long row, spaced $25 \mathrm{~cm}$ apart. Wheat cultivar Mingxian169 was planted around the $\mathrm{F}_{2}$ population as susceptible control and inoculum spreader. In late March of the next year, the spreader rows were artificially inoculated by the mixture of Blumeria graminis f. sp. tritici isolates prevalent in northern China. In May, when the susceptible control Mingxian169 exhibited serious disease symptoms, the evaluation of the powdery mildew reactions at heading and grain filling stages was recorded using a 0-9 scale, where $0-4$ was considered as resistant and 5-9 as susceptible [69].

\section{Application of KASP markers in MAS}

The 1RS-specific KASP marker SWK5282 was used to screen a natural population with 161 wheat cultivars/ lines to determine the distribution of 1RS translocation lines therein. For the verification of the accuracy and stability of the KASP marker, the corresponding PCR-based 1RS-specific marker SW5282 was also used to identify these 161 wheat cultivars/lines. In addition, the KASP marker SWK252224 specific for 2RL was applied in detecting chromosome 2RL in $F_{2}$ individuals of 'WR91 $\times$ Shixin 633'. Meanwhile, the corresponding PCR-based marker SW252224 was also used to test the $F_{2}$ population to confirm the result of SWK252224. Chinese Spring and Imperial were used as the KASP marker genotyping controls.

\section{Supplementary information}

Supplementary information accompanies this paper at https://doi.org/10. 1186/s12864-020-6624-y.

Additional file 1: Table S1. Primer sequences of the 404 molecular markers specific for 14 rye chromosome arms. 
Additional file 2: Table S2. Detection of 1RS translocations in 161 wheat cultivars/ lines.

\section{Abbreviations}

FISH: Fluorescence in situ hybridization; GISH: Genomic in situ hybridization; KASP: Kompetitive allele-specific PCR; MAS: Marker-assisted selection; mcFISH: Multicolor FISH; ND-FISH: Non-denaturing FISH; NGS: Next-generation sequencing; SLAF-seq: Specific-locus amplified fragment sequencing; SNP: Single nucleotide polymorphism

\section{Acknowledgements}

The authors are grateful to the following researchers for their providing valuable plant materials: Dr. Zongxiang Tang (Sichuan Agricultural University, Chengdu, CHN), Dr. John Raupp (Kansas State University, Manhattan, U.S.), Dr Lifang Zhuang (Nanjing Agricultural University, Nanjing, CHN), Dr. Adrian Turner (John Innes Centre, Norwich, UK), and Dr. Yiwen Li (Institute of Genetics and Developmental Biology, Chinese Academy of Sciences, Beijing, (HN)

\section{Author's contributions}

DGA, GHH and PTM designed the research. GHH, SYL, HL and JW analyzed the data. GHH, SYL, YLJ and MSJ performed the experiments. GHH and SYL wrote the article. DGA supervised and revised the writing of the article. All authors have read and approved the final manuscript.

\section{Funding}

This research was financially supported by the Strategic Priority Research Program of the Chinese Academy of Sciences No. XDA24030102, the National Key Research and Development Program of China No. 2016YFD0102002, and the National Natural Science Foundation of China No. 31771793. The funders had no role in the designing and conducting of this study and collection, analysis, and interpretation of data and in writing the manuscript.

\section{Availability of data and materials}

All the data generated or analyzed during the current study were included in the manuscript and its additional files. The raw data is available from the corresponding author on reasonable request.

\section{Ethics approval and consent to participate}

Not applicable.

\section{Consent for publication}

Not applicable.

\section{Competing interests}

The authors declare that they have no conflict of interests.

\section{Author details}

${ }^{1}$ Center for Agricultural Resources Research, Institute of Genetics and Developmental Biology, Chinese Academy of Sciences, Shijiazhuang 050021, Hebei, China. ${ }^{2}$ University of Chinese Academy of Sciences, Beijing 100049, China. ${ }^{3}$ School of Life Sciences, Yantai University, Yantai 264005, Shandong, China. ${ }^{4}$ The Innovative Academy of Seed Design, Chinese Academy of Sciences, Beijing, China.

Received: 19 December 2019 Accepted: 25 February 2020 Published online: 04 March 2020

\section{References}

1. International Wheat Genome Sequencing Consortium (IWGSC). A chromosome-based draft sequence of the hexaploid bread wheat (Triticum aestivum) genome. Science. 2014:345:1251788.

2. Gupta PK, Langridge P, Mir RR. Marker-assisted wheat breeding: present status and future possibilities. Mol Breed. 2010;26(2):145-61.

3. Mujeeb-Kazi A, Kazi AG, Dundas I, Rasheed A, Ogbonnaya F, Kishii M, Bonnett D, Wang RR-C, Xu S, Chen PD, et al. Genetic diversity for wheat improvement as a conduit for food security. Adv Agron. 2013;122:179-257.
4. Friebe B, Jiang J, Raupp WJ, Mclntosh RA, Gill BS. Characterization of wheatalien translocations conferring resistance to diseases and pests: current status. Euphytica. 1996;91(1):59-87.

5. Colmer TD, Flowers TJ, Munns R. Use of wild relatives to improve salt tolerance in wheat. J Exp Bot. 2006;57(5):1059-78.

6. Wang HY, Dai K, Xiao J, Yuan CX, Zhao RH, Doležel J, Wu YF, Cao AZ, Chen PD, Zhang SZ, et al. Development of intron targeting (IT) markers specific for chromosome arm 4VS of Haynaldia villosa by chromosome sorting and next-generation sequencing. BMC Genomics. 2017;18:167.

7. Zhang Z, Han HM, Liu WH, Song LQ, Zhang JP, Zhou SH, Yang XM, Li XQ, Li $\mathrm{LH}$. Deletion mapping and verification of an enhanced-grain number per spike locus from the 6PL chromosome arm of Agropyron cristatum in common wheat. Theor Appl Genet. 2019;132(10):2815-27.

8. Mago R, Miah H, Lawrence GJ, Wellings CR, Spielmeyer W, Bariana HS, McIntosh RA, Pryor AJ, Ellis JG. High-resolution mapping and mutation analysis separate the rust resistance genes Sr31, Lr26 and Yrg on the short arm of rye chromosome 1. Theor Appl Genet. 2005:112(1):41-50.

9. Mclntosh RA, Zhang P, Cowger C, Parks R, Lagudah ES, Hoxha S. Ryederived powdery mildew resistance gene $P m 8$ in wheat is suppressed by the Pm3 locus. Theor Appl Genet. 2011;123(3):359-67.

10. Kumlay AM, Baenziger PS, Gill KS, Shelton DR, Graybosch RA, Lukaszewski AJ, Wesenberg DM. Understanding the effect of rye chromatin in bread wheat. Crop Sci. 2003;43(5):1643-51.

11. Ren TH, Chen F, Yan BJ, Zhang HQ, Ren ZL. Genetic diversity of wheat-rye 1BL-1RS translocation lines derived from different wheat and rye sources. Euphytica. 2012;183(2):133-46.

12. Schneider A, Rakszegi M, Molnár-Láng M, Szakács É. Production and cytomolecular identification of new wheat-perennial rye (Secale cereanum) disomic addition lines with yellow rust resistance (6R) and increased arabinoxylan and protein content (1R, 4R, 6R). Theor Appl Genet. 2016;129(5):1045-59.

13. Tester $M$, Langridge $P$. Breeding technologies to increase crop production in a changing world. Science. 2010;327:818-22.

14. Friebe B, Heun M, Tuleen N, Zeller FJ, Gill BS. Cytogenetically monitored transfer of powdery mildew resistance from rye into wheat. Crop Sci. 1994;34(3):621-5.

15. Singh A, Pallavi JK, Gupta P, Prabhu KV. Identification of microsatellite markers linked to leaf rust resistance gene Lr25 in wheat. J Appl Genet. 2012;53(1):19-25.

16. McIntosh RA, Friebe B, Jiang J, The D, Gill BS. Cytogenetical studies in wheat $\mathrm{XVI}$. Chromosome location of a new gene for resistance to leaf rust in a Japanese wheat-rye translocation line. Euphytica. 1995;82(2):141-7.

17. Rahmatov M, Rouse MN, Nirmala J, Danilova T, Friebe B, Steffenson BJ, Johansson E. A new 2DS.2RL Robertsonian translocation transfers stem rust resistance gene Sr59 into wheat. Theor Appl Genet. 2016;129(7):1383-92.

18. Zhuang QS. Chinese wheat improvement and pedigree analysis. Beijing: Chinese Agriculture Press; 2003.

19. Hao M, Liu M, Luo JT, Fan CL, Yi YJ, Zhang LQ, Yuan ZW, Ning SZ, Zheng $Y L$, Liu DC. Introgression of powdery mildew resistance gene Pm56 on rye chromosome arm 6RS into wheat. Front Plant Sci. 2018:9:1040.

20. An DG, Ma PT, Zheng Q, Fu SL, Li LH, Han FP, Han GH, Wang J, Xu YF, Jin $Y L$, et al. Development and molecular cytogenetic identification of a new wheat-rye $4 R$ chromosome disomic addition line with resistances to powdery mildew, stripe rust and sharp eyespot. Theor Appl Genet. 2019; 132:257-72

21. An DG, Li LH, Li JM, Li HJ, Zhu YG. Introgression of resistance to powdery mildew conferred by chromosome $2 \mathrm{R}$ by crossing wheat nullisomic $2 \mathrm{D}$ with rye. J Integr Plant Biol. 2006:48(7):838-47.

22. An DG, Zheng Q, Zhou YL, Ma PT, Lv ZL, Li LH, Li B, Luo QL, Xu HX, Xu YF. Molecular cytogenetic characterization of a new wheat-rye $4 R$ chromosome translocation line resistant to powdery mildew. Chromosom Res. 2013;21(4):419-32.

23. Hechanova SL, Prusty MR, Kim SR, Ballesfin L, Ramos J, Prahalada GD, Jena KK. Monosomic alien addition lines (MAALs) of Oryza rhizomatis in Oryza sativa: production, cytology, alien trait introgression, molecular analysis and breeding application. Theor Appl Genet. 2018;131(45):2197-211.

24. Xu HX, Yin DD, Li LH, Wang QX, Li XQ, Yang XM, Liu WH, An DG. Development and application of EST-based markers specific for chromosome arms of rye (Secale cereale L.). Cytogenet Genome Res. 2012;136(3):220-8.

25. Li JJ, Endo TR, Saito M, Ishikawa G, Nakamura T, Nasuda S. Homoeologous relationship of rye chromosome arms as detected with wheat PLUG markers. Chromosoma. 2013:122(6):555-64.

26. Martis MM, Zhou RN, Haseneyer G, Schmutzer T, Vrána J, Kubaláková M, König S, Kugler KG, Scholz U, Hackauf B, et al. Reticulate evolution of the rye genome. Plant Cell. 2013;25(10):3685-98. 
27. Qiu L, Tang ZX, Li M, Fu SL. Development of new PCR-based markers specific for chromosome arms of rye (Secale cereale L). Genome. 2016;59(3):159-65.

28. Li JJ, Zhou RN, Endo TR, Stein N. High-throughput development of SSR marker candidates and their chromosomal assignment in rye (Secale cereale L.). Plant Breed. 2018;137:561-72.

29. Chikmawati T, Miftahudin M, Skovmand B, Gustafson JP. Amplified fragment length polymorphism-based genetic diversity among cultivated and weedy rye (Secale cereale L.) accessions. Genet Resour Crop Evol. 2012;59(8):1743-52.

30. Targońska M, Bolibok-Brągoszewska H, Rakoczy-Trojanowska M. Assessment of genetic diversity in Secale cereale based on SSR markers. Plant Mol Biol Rep. 2016;34(1):37-51.

31. Wu JH, Wang QL, Kang ZS, Liu SJ, Li HY, Mu JM, Dai MF, Han DJ, Zeng QD, Chen XM. Development and validation of KASP-SNP markers for QTL underlying resistance to stripe rust in common wheat cultivar P10057. Plant Dis. 2017;101:2079-87.

32. Ma FF, Xu YF, Ma ZQ, Li LH, An DG. Genome-wide association and validation of key loci for yield-related traits in wheat founder parent Xiaoyan 6. Mol Breed. 2018;38(7):91.

33. Qureshi N, Kandiah P, Gessese MK, Nsabiyera V, Wells V, Babu P, Wong D, Hayden M, Bariana H, Bansal U. Development of co-dominant KASP markers co-segregating with Ug99 effective stem rust resistance gene Sr26 in wheat. Mol Breed. 2018;38(8):97.

34. Ma HH, Zhang JP, Zhang J, Zhou SH, Han HM, Liu WH, Yang XM, Li XQ, Li LH Development of P genome-specific SNPs and their application in tracing Agropyron cristatum introgressions in common wheat. The Crop J. 2019;37:151-62.

35. International Wheat Genome Sequencing Consortium (IWGSC). Shifting the limits in wheat research and breeding using a fully annotated reference genome. Science. 2018;361:eaar7191.

36. Bauer E, Schmutzer T, Barilar I, Mascher M, Gundlach H, Martis MM, Twardziok SO, Hackauf B, Gordillo A, Wilde P, et al. Towards a wholegenome sequence for rye (Secale cereale L.). Plant J. 2017;89(5):853-69

37. An DG, Zheng Q, Luo QL, Ma PT, Zhang HX, Li LH, Han FP, Xu HX, Xu YF, Zhang XT. Molecular cytogenetic identification of a new wheat-rye $6 R$ chromosome disomic addition line with powdery mildew resistance. PLoS One. 2015;10(8):e0134534.

38. Yang WJ, Wang CY, Chen CC, Wang YJ, Zhang H, Liu XL, Ji WQ. Molecular cytogenetic identification of a wheat-rye $1 R$ addition line with multiple spikelets and resistance to powdery mildew. Genome. 2016;59(4):277-88.

39. Ren TH, Ren ZL, Yang MY, Yan BJ, Tan FQ, Fu SL, Tang ZX, Li Z. Novel source of 1RS from Baili rye conferred high resistance to diseases and enhanced yield traits to common wheat. Mol Breed. 2018;38(8):101.

40. Ren TH, Li Z, Yan BJ, Tan FQ, Tang ZX, Fu SL, Yang MY, Ren ZL. Targeted segment transfer from rye chromosome $2 \mathrm{R}$ to wheat chromosomes $2 \mathrm{~A}, 2 \mathrm{~B}$, and 7B. Cytogenet Genome Res. 2017;151(1):50-9.

41. Du HM, Tang ZX, Duan Q, Tang SY, Fu SL. Using the 6RLK ${ }^{u}$ minichromosome of rye (Secale cereale L.) to create wheat-rye 6D/6RL ${ }^{\mathrm{Ku}}$ small segment translocation lines with powdery mildew resistance. Inter $\rfloor$ of Mol Sci. 2018;19(12):3933.

42. Guo JT, Lei YH, Zhang HT, Song DH, Liu X, Cao ZL, Chu CG, Zhuang LF, Qi ZJ. Frequent variations in tandem repeats pSc200 and pSc119.2 cause rapid chromosome evolution of open-pollinated rye. Mol Breed. 2019:39:133.

43. Camacho MV, Matos M, Gonzáles C, Pérez-Flores V, Pernauta B, Pinto-Carnide $\mathrm{O}$, Benito C. Secale cereale inter-microsatellites (SCIMs): chromosomal location and genetic inheritance. Genetica. 2005;123(3):303-11.

44. Tomita M, Seno A. Rye chromosome-specific polymerase chain reaction products developed by primers designed from the EcoO109l recognition site. Genome. 2012;55(5):370-82.

45. Wu N, Li M, Sun HX, Cao ZL, Liu P, Ding TC, Xu HB, Chu CG, Zhuang LF, Qi ZJ. RNA-seq facilitates development of chromosome-specific markers and transfer of rye chromatin to wheat. Mol Breed. 2018;38(1):6.

46. Zhang $Y X$, Wang $L H$, Xin $H G$, Li DH, Ma CX, Ding X, Hong WG, Zhang XR. Construction of a high-density genetic map for sesame based on large scale marker development by specific length amplified fragment (SLAF) sequencing. BMC Plant Biol. 2013;13:141

47. Li M, Tang ZX, Qiu L, Wang YY, Tang SY, Fu SL. Identification and physical mapping of new PCR-based markers specific for the long arm of rye (Secale cereale L.) chromosome 6. J Genet Genom. 2016;3(4):199-206.

48. Liu LQ, Luo QL, Teng W, Li B, Li HW, Li YW, Li ZS, Zheng Q. Development of Thinopyrum ponticum-specific molecular markers and FISH probes based on SLAF-seq technology. Planta. 2018;247:1099-108.
49. Winfield MO, Allen AM, Burridge AJ, Barker GLA, Benbow HR, Wilkinson PA, Coghill J, Waterfall C, Davassi A, Scopes G, et al. High-density SNP genotyping array for hexaploid wheat and its secondary and tertiary gene pool. Plant Biotechnol J. 2016;14(5):1195-206.

50. King J, Grewal S, Yang CY, Hubbart-Edwards S, Scholefield DC, Ashling S, Edwards $\mathrm{K}$, Allen AM, Burridge A, Bloor C, et al. A step change in the transfer of interspecific variation into wheat from Ambylopyrum muticum. Plant Biotechnol J. 2017;15(2):217-26.

51. Grewal S, Hubbart-Edwards S, Yang CY, Scholefield DC, Ashling S, Burridge AJ, Wilkinson PA, King IP, King J. Detection of T urartu introgressions in wheat and development of a panel of interspecific introgression lines. Front Plant Sci. 2018;9:1565.

52. Grewal S, Yang CY, Hubbart-Edwards S, Scholefield DC, Ashling S, Burridge AJ, King IP, King J. Characterisation of Thinopyrum bessarabicum chromosomes through genome-wide introgressions into wheat. Theor Appl Genet. 2018;131(2):389-406.

53. King J, Grewal S, Yang CY, Hubbart-Edwards S, Scholefield DC, Ashling S, Harper JA, Allen AM, Edwards KJ, Burridge A, et al. Introgression of Aegilops speltoides segments in Triticum aestivum and the effect of the gametocidal genes. Ann Bot. 2018;121(2):229-40.

54. Rasheed A, Hao YF, Xia XC, Khan A, Xu YB, Varshney RK, He ZH. Crop breeding chips and genotyping platforms: progress, challenges, and perspectives. Mol Plant. 2017;10(8):1047-64.

55. Semagn K, Babu R, Hearne S, Olsen M. Single nucleotide polymorphism genotyping using kompetitive allele specific PCR (KASP): overview of the technology and its application in crop improvement. Mol Breed. 2014;33(1):1-14.

56. Tiwari VK, Wang SC, Sehgal S, Vrána J, Friebe B, Kubaláková M, Chhuneja P, Doležel J, Akhunov E, Kalia B, et al. SNP discovery for mapping alien introgressions in wheat. BMC Genomics. 2014;15:273.

57. Grewal S, Hubbart-Edwards S, Yang CY, Devi U, Baker L, Heath J, Ashling S, Scholefield DC, Howells C, Yarde J, et al. Rapid identification of homozygosity and site of wild relative introgressions in wheat through chromosome-specific KASP genotyping assays. Plant Biotechnol J. 2019. https//doi.org/10.1111/pbi.13241.

58. Zeller FJ, Gunzel G, Fischbeck G, Gerstenkom P, Weipert D. Veranderungen der Backeigenschaften des Weizens durch die Weizen-RoggenChromosomentranslokation 1B/1R. Getreide Mehl Und Brot. 1982;36:141-3.

59. Ma PT, Han GH, Zheng Q, Liu SY, Han FP, Wang J, Luo QL, An DG. Development of novel wheat-rye chromosome $4 \mathrm{R}$ translocations and assignment of their powdery mildew resistance. Plant Dis. 2019. https://doi. org/10.1094/PDIS-01-19-0160-RE.

60. Chen PD, You CF, Hu Y, Chen SW, Zhou B, Cao AZ, Wang XE. Radiationinduced translocations with reduced Haynaldia villosa chromatin at the Pm21 locus for powdery mildew resistance in wheat. Mol Breed. 2013;31(2):477-84.

61. Danilova TV, Friebe B, Gill BS, Poland J, Jackson E. Development of a complete set of wheat-barley group-7 Robertsonian translocation chromosomes conferring an increased content of b-glucan. Theor Appl Genet. 2018;131:377-88.

62. Gill KS, Lubbers EL, Gill BS, Raupp WJ, Cox TS. A genetic linkage map of Triticum tauschii (DD) and its relationship to the D genome of bread wheat (AABBDD). Genome. 1991;34(3):362-74.

63. Sun XW, Liu DY, Zhang XF, Li WB, Liu H, Hong WG, Jiang CB, Guan N, Ma CX, Zeng HP, et al. SLAF-seq: an efficient method of large-scale de novo snp discovery and genotyping using high-throughput sequencing. PLoS One. 2013;8:e58700.

64. Li RQ, Yu C, Li YR, Lam TW, Yiu SM, Kristiansen K, Wang J. SOAP2: an improved ultrafast tool for short read alignment. Bioinformatics. 2009;25(15):1966-7.

65. Han FP, Gao Z, Birchler JA. Centromere inactivation and reactivation reveals both epigenetic and genetic components for centromere specification. Plant Cell. 2009;21:1929-39.

66. Tang ZX, Yang ZJ, Fu SL. Oligonucleotides replacing the roles of repetitive sequences pAs1, pSc119.2, pTa-535, pTa71, CCS1, and pAWRC.1 for FISH analysis. J Appl Genet. 2014;55:313-8.

67. Krzywimski M, Schein J, Birol I, Connors J, Gascoyne R, Horsman D, Jones SJ, Marra MA. Circos: An information aesthetic for comparative genomics. Genome Res. 2009;19(9):1639-45.

68. Ma PT, Xu HX, Xu YF, Song LP, Liang SS, Sheng Y, Han GH, Zhang XT, An DG. Characterization of a powdery mildew resistance gene in wheat breeding line 10V-2 and its application in marker-assisted selection. Plant Dis. 2018;102(5):925-31.

69. Sheng BQ, Duan XY. Improvement of scale 0-9 method for scoring adult plant resistance to powdery mildew of wheat. Beijing Agric Sci. 1991;1:38-9.

\section{Publisher's Note}

Springer Nature remains neutral with regard to jurisdictional claims in published maps and institutional affiliations. 